Огляди літератури, оригінальні дослідження, погляд на проблему, випадок з практики, короткі повідомлення УДК 616-001.5

DOI 10.11603/1811-2471.2020.v.i2.11333

\title{
СУДЕБНО-МЕДИЦИНСКАЯ ХАРАКТЕРИСТИКА ПОВРЕЖДЕНИЙ ОРГАНОВ СЛУХА
}

\author{
ФМ. Р. Расулова, С. И. Индиаминов \\ Самаркандский государственный медицинский институт, узбекистан
}

РЕЗЮМЕ. Повреждение органов слуха является одной из частых патологий, составляющей 5,7 \% среди всех травм ЛОР органов. Судебно-медицинские аспекты повреждений органов слуха изучены недостаточно. Не разработаны критерии по определению степени тяжести, давности и оценки механизма травмы при повреждениях органов слуха.

Цель - изучение структуры и критериев оценки степени тяжести механических повреждений органов слуха.

Материал и методы. Изучены материалы дела, медицинские документы, результаты дополнительных исследований и заключений (актов) судебно-медицинских экспертиз 92 случаев, связанных с механическими травмами органов слуха. При подозрении на повреждения среднего или внутреннего уха проведены консультация лОР-специалистов и дополнительные методы исследования с целью определения степени тяжести утраты функции слуха и наличия сопутствующих повреждений смежных органов. Для оценки органов слуха и смежных структур в пределах височной кости, а также структур внутреннего уха, проводили рентгенографию черепа в боковой проекции, аудиологические исследования и МРТ. При сочетанных повреждениях для оценки состояния височной кости и костных структур внутреннего уха проводили КТ или МСКТ височной кости в спиральном режиме в аксиальной проекции.

Результаты. При распределении травм в зависимости от пола пострадавших выявлено, что повреждения органов слуха отмечаются преимущественно у лиц мужского пола, составляя 97 \%. Наиболее часто повреждения отмечались в возрасте 18-35 лет (72,3 \%). При выяснении обстоятельства травмы выявлено, что в 68 (73,9 \%) случаях повреждения были получены в результате бытовой и уличной травмы, в $24(26,1 \%)$ случаях при автомобильной травме внутри салона. Среди повреждений органов слуха (92) преобладали повреждения наружного отдела уха (81), а повреждения среднего и внутреннего уха отмечены значительно реже. Установлено, что от воздействия тупых твердых предметов в основном повреждались наружное и среднее ухо. Повреждения внутреннего уха (лабиринта) и пирамиды височной кости наблюдались при тяжелых сочетанных черепно-мозговых травмах.

Выводы. Травмы органов слуха чаще наблюдаются у лиц мужского пола. Среди основных причин травматических повреждений можно выделить бытовую и уличную травму. Критериями оценки степени тяжести повреждений наружного уха могут быть длительность расстройства здоровья, а среднего уха - объем стойкой утраты общей трудоспособности с учетом наличия сочетанных травм. Травматические повреждения БП восстановились у 100 \% исследованных. Обоснование степени тяжести повреждений возможно при проведении комплексных исследований: клинических, аудиологических, рентгенологических, КТ или МСКТ исследований.

КЛЮЧЕВЫЕ СЛОВА: орган слуха; повреждения; судебно-медицинская оценка.

Вступление. Повреждения органов слуха являются одними из частых патологий, которые составляют 5,7 \% среди всех травм ЛОР органов. Судебно-медицинские аспекты повреждений органов слуха изучены недостаточно. Не разработаны критерии по определению степени тяжести, давности и оценки механизма травмы при повреждениях органов слуха с учётом не только характера повреждения, но и сопутствующих повреждений или заболеваний, возможных осложнений, последствий травм [1, 2].

Цель - изучение структуры и критериев оценки степени тяжести механических повреждений органов слуха.

Материал и методы исследования. Изучены материалы дела, медицинские документы, результаты дополнительных исследований и заключений (актов) судебно-медицинских экспертиз 92 случаев, связанных с механическими травмами органов слуха.

Экспертная оценка повреждений органов слуха основывалась на объективном обследова- нии пострадавших. При этом оценивали состояние кожных покровов и мягких тканей, форму ушной раковины, отсутствие или наличие наружных органов слуха. Для детального изучения характера повреждений на барабанной перепонке (БП) условно ее делили на четыре части - квадранты. Квадранты образованы при пересечении двух линий: прямой линии через рукоятку молоточка и перпендикулярной ей прямой линии, проведенной через пупок. В практике выделяют: передне-нижний, передне-верхний, задне-нижний и задне-верхний квадранты. При подозрении на повреждения среднего или внутреннего уха проведены консультации ЛОР-специалистов и использованы дополнительные методы исследования с целью определения степени тяжести утраты функции слуха и наличия сопутствующих повреждений смежных органов. Для оценки органов слуха и смежных структур в пределах височной кости, а также структур внутреннего уха проводили рентгенографию черепа в боковой проекции, аудиологические исследования и МРТ. При соче- 
Огляди літератури, оригінальні дослідження, погляд на проблему, випадок з практики, короткі повідомлення

танных повреждениях для оценки состояния височной кости и костных структур внутреннего уха проводили КТ или МСКТ височной кости в спиральном режиме в аксиальной проекции.

Результаты и их обсуждение. При распределении травм в зависимости от пола пострадавших выявлено, что повреждения органов слуха отмечаются преимущественно у лиц мужского пола (97 \%). Наиболее часто повреждения отмечались в возрасте 18-35 лет (72,3 \%). При выяснении обстоятельств травмы выявлено, что в 68 (73,9 \%) случаях повреждения были получены в результате бытовой и уличной травмы, в 24 (26,1 \%) случаях - при автомобильной травме внутри салона. Среди повреждений органов слуха (92) преобладали повреждения наружного отдела уха (81), а повреждения среднего и внутреннего уха отмечены значительно реже и были обнаружены соответственно у 8 и 3 пострадавших.

Установлено, что от воздействия тупых твердых предметов в основном повреждалась наружное и среднее ухо. Во всех случаях повреждения были односторонними. При этом в 17 случаях отмечены ссадины, в 30 - кровоподтеки, в 10 - с ушибами мягких тканей, в 24 - раны в области ушной раковины и наружного слухового прохода. В 8 $(8,7$ \%) случаях, наряду с повреждениями мягких

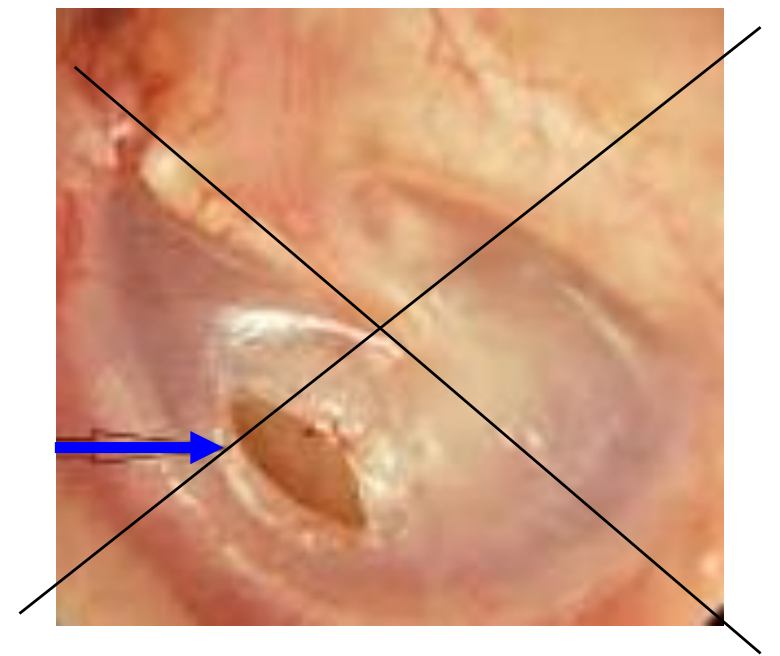

Рис. 1. Локальный разрыв барабанной перепонки в задне-нижнем квадранте.

В зависимости от срока края повреждений становились ровными, фестончатыми белесовато-серого цвета. При определении площади повреждения БП использовали расчет по квадрантам: общая площадь БП была принята за 100 \%, каждый квадрант составлял 25 \%. У большинства пострадавших площадь поражения БП составила до 50 \% (6), и только у 2 - более $50 \%$.

Отмечено, что перфорация БП, занимавшая менее 25 \% (2) площади, восстанавливалась че- тканей, травма уха сопровождалась разрывом барабанной перепонки. Повреждения внутреннего уха (лабиринта) и пирамиды височной кости наблюдались при тяжелых сочетанных черепно-мозговых травмах (3 случая).

Ссадины отмечены по всей поверхности ушной раковины в виде локальных и распространенных повреждений линейной, полуовальной формы. Кровоподтеки с ушибами мягких тканей располагались в области завитка, противозавитка и мочки уха. Ушибленные раны ушной раковины выявлены при автомобильных травмах внутри салона, они характеризовались наличием неровных отвислых стенок, осадненной поверхности и выраженного отека, локализовались в области завитка и противозавитка.

Для оценки механизма травм БП учитывали локализацию повреждений в её квадрантах. Выявлено, что 6 случаев травматических повреждений БП определялись в заднее-нижнем квадранте, что объясняется анатомическими особенностями слухового прохода (рис. 1).

Повреждения БП в переднее-верхнем и переднее-нижнем квадрантах наблюдались только в 2 случаях. Форма перфорации травмированной БП имела округлую, треугольную или щелевидную форму с ровными или фестончатыми краями (рис. 2).

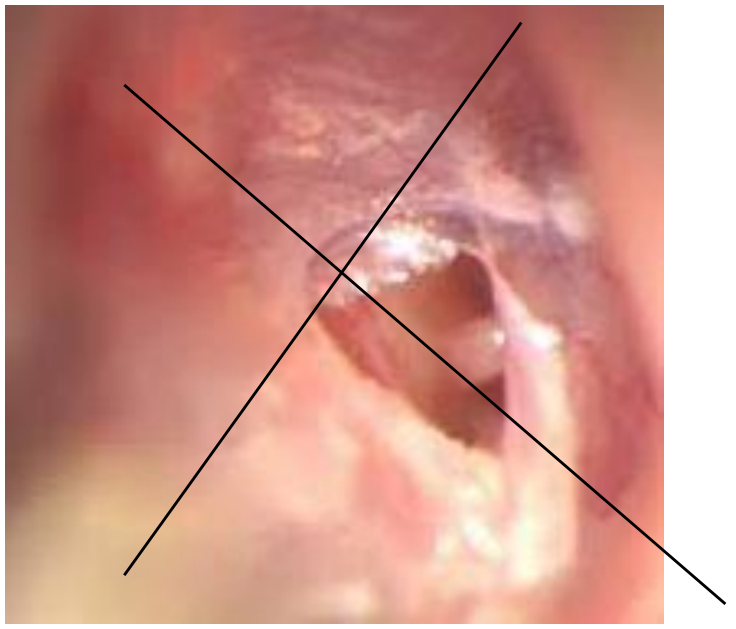

Рис. 2. Разрыв барабанной перепонки с фестончатыми краями.

рез 7-10 суток. Восстановление субтотальных перфораций, которые занимали от 25 до 50 \% площади (4), составляло 10-14 дней, перфораций, занимающих более 50 \% площади БП (2) - 21 день. Разрыв БП от воздействия тупого предмета оценивался по критерию длительности расстройства здоровья и утраты общей трудоспособности как повреждения легкой степени, вызвавшее расстройство здоровья на срок от 6 до 21 дня. У всех пострадавших с перфорацией БП отмечено сни- 
Огляди літератури, оригінальні дослідження, погляд на проблему, випадок з практики, короткі повідомлення жение слуха от 1000 Гц до 40 Дб, оценено по критерию утраты обшей трудоспособности на 5 \%, как легкие телесные повреждения, повлекшее за собой кратковременное расстройства здоровья.

В 8 (8,7 \%) случаях, помимо повреждений уха, у пострадавших отмечены также переломы носа и смежных его структур, в 3 (3,3 \%) - переломы костей черепа, переломы верхних - у 5 (5,4 \%) и нижних конечностей - у 2 (2,2\%), переломы ребер у 3 (3,3\%) пострадавших, в 71 $(77,1 \%)$ случае повреждений костей в других системах не отмечено.

Повреждения уха с сопутствующими переломами носа и смежных его структур (8,7 \%), переломами 3 ребер (3,3 \%), костей верхних (5,4\%) и (2,8 \%) нижних конечностей, оценены по критерию длительности расстройства здоровья как средней степени тяжести, вызвавшие расстройство здоровья на срок более 21 дня и менее 4 месяцев. Повреждения органов слуха, сопровождающиеся переломами костей черепа (3,3 \%) и признаками сотрясения и ушиба головного мозга оценены как тяжкие телесные повреждения по признаку опасности для жизни.

Повреждения внутреннего уха (лабиринта) и пирамиды височной кости отмечались относительно редко и выявлены при тяжелых черепно-

\section{ЛИТЕРАТУРА}

1. Блоцкий А. А. Травмы и инородные тела лОР органов / А. А. Блоцкий, В. В. Антипенко, Р. А. Блоцкий. Благовещенск, 2018. - 214 с.

2. Родионова О. И. Травматическая перфорация барабанной перепонки / О. И. Родионова, А. В. Ярута // Военная медицина. - 2018. - № 2. - С. 31-33.

\section{REFERENCES}

1. Blotskyy, A.A., Antipenko, V.V., \& Blotskyy, R.A. (2018). Travmy i inorodnye tela LOR organov [ENT injuries and foreign bodies]. Blagoveshchensk [in Russian].

мозговых травмах, сопровождающихся переломами основания черепа и пирамиды височной кости. При этом на фоне тяжелого общего состояния пострадавших диагностика повреждений органов слуха, особенно в ранние сроки после травмы, была затруднительна. В связи с этим повреждения органов слуха в 2 (66,7 \%) случаях диагностировались поздно, после стабилизации общего состояния больного, и в 1 (33,3 \%) случае не диагностированы в клинике. При судебно-медицинской экспертизе состояние потерпевших во всех случаях оценено по доминирующим повреждениям и состояниям, вызвавшим угрозу для жизни.

Выводы. Травмы органов слуха чаще наблюдаются у лиц мужского пола. Среди основных причин травматических повреждений можно выделить бытовую и уличную травму. Критериями оценки степени тяжести повреждений наружного уха могут быть длительность расстройства здоровья, а среднего уха - объем стойкой утраты общей трудоспособности с учетом наличия сочетанных травм. Травматические повреждения БП восстановилась у всех (100\%) исследованных. Обоснование степени тяжести повреждений возможно при проведении комплексных исследований: клинических, аудиологических, рентгенологических, КТ или МСКТ исследований.

\section{СУДОВО-МЕДИЧНА ХАРАКТЕРИСТИКА УШКОДЖЕНЬ ОРГАНІВ СЛУХУ}

2. Rodionova, O.I., \& Yaruta, A.V. (2018). Travmaticheskaya perforatsiya barabannoy pereponki [Traumatic perforation of the tympanic membrane]. Voyennaya meditsina Military Medicine, 2, 31-33 [in Russian].

\section{๑М. Р. Расулова, С. І. Індіамінов \\ Самаркандський державний медичний інститут, Узбекистан}

РЕзЮМЕ. Пошкодження органів слуху є однією з найчастіших патологій, що становить 5,7 \% серед усіх травм лОР органів. Судово-медичні аспекти пошкоджень органів слуху вивчені недостатньо. Не розроблені критерії щодо визначення ступеня тяжкості, давності й оцінки механізму травми при пошкодженнях органів слуху.

Мета - вивчення структури і критеріїв оцінки ступеня тяжкості механічних пошкоджень органів слуху.

Матеріал і методи. Вивчено матеріали справи, медичні документи, результати додаткових досліджень і висновків (актів) судово-медичних експертиз 92 випадків, пов'язаних з механічними травмами органів слуху. При підозрі на ушкодження середнього чи внутрішнього вуха проведені консультація лОР-спеціалістів та додаткові методи дослідження з метою визначення ступеня тяжкості втрати функції слуху і наявності супутніх ушкоджень суміжних органів. Для оцінки органів слуху та суміжних структур в межах скроневої кістки, а також структур внутрішнього вуха, проводили рентгенографію черепа в бічній проекції, аудіологічні дослідження і МРТ. При поєдна- 
Огляди літератури, оригінальні дослідження, погляд на проблему, випадок з практики, короткі повідомлення них пошкодженнях для оцінки стану скроневої кістки і кісткових структур внутрішнього вуха проводили КТ або МСКТ скроневої кістки в спіральному режимі в аксіальній проекції.

Результати. При розподілі травм в залежності від статі постраждалих виявлено, що пошкодження органів слуху відзначаються переважно у осіб чоловічої статі, складаючи 97 \%. Найчастіше пошкодження відзначалися у віці 18-35 років (72,3 \%). При з'ясуванні обставин травми виявлено, що в 68 (73,9 \%) випадках пошкодження були отримані в результаті побутової та вуличної травми, в 24 (26,1 \%) випадках - при автомобільній травмі всередині салону. Серед пошкоджень органів слуху (92) переважали пошкодження зовнішнього відділу вуха (81), а пошкодження середнього і внутрішнього вуха відзначені значно рідше. Встановлено, що від впливу тупих твердих предметів в основному ушкоджувалися зовнішнє і середнє вухо. Пошкодження внутрішнього вуха (лабіринту) і піраміди скроневої кістки спостерігалися при тяжких поєднаних черепно-мозкових травмах.

Висновки. Травми органів слуху частіше спостерігаються в осіб чоловічої статі. Серед основних причин травматичних пошкоджень можна виділити побутову та вуличну травми. Критеріями оцінки ступеня тяжкості ушкоджень зовнішнього вуха можуть бути тривалість розладу здоров'я, а середнього вуха - обсяг стійкої втрати загальної працездатності з урахуванням наявності поєднаних травм. Травматичні пошкодження БП відновилися у 100 \% обстежених. Обґрунтування ступеня тяжкості ушкоджень можливе при проведенні комплексних досліджень: клінічних, аудіологічних, рентгенологічних, КТ або МСКТ досліджень.

КЛючовІ СлОвА: орган слуху; пошкодження; судово-медична оцінка.

\section{FORENSIC CHARACTERISTIC OF HEARING INJURIES}

\section{@M. R. Rasulova, S. I. Indiaminov \\ Samarkand State Medical Institute, Uzbekistan}

SUMMARY. Hearing injuries are one of the rare pathologies, which accounts for $5.7 \%$ of all injuries of ENT organs. Forensic aspects of hearing damage are not well understood. Criteria have not been developed for determining the severity, prescription and assessment of the mechanism of trauma in case of damage to hearing organs.

The aim - to study the structure and criteria for assessing the severity of mechanical damage to hearing organs.

Material and Methods. The case materials, medical documents, the results of additional studies and conclusions (acts) of forensic medical examinations of 92 cases related to mechanical injuries of the hearing organs were studied. If there is a suspicion of damage to the middle or inner ear, an ENT specialist was consulted and additional research methods were conducted to determine the severity of the loss of hearing function and the presence of concomitant damage to adjacent organs. To assess the hearing organs and adjacent structures within the temporal bone, as well as the structures of the inner ear, X-ray of the skull was performed in lateral projection, audiological studies and MRI. In case of combined injuries, CT or MSCT of the temporal bone in a spiral mode in axial projection was performed to assess the condition of the temporal bone and bone structures of the inner ear.

Results. When distributing injuries depending on the gender of the victims, it was revealed that damage to the organs of hearing was noted mainly in males, amounting to $97 \%$. Most often, injuries were noted at the age of 18-35 years (72.3\%). When clarifying the circumstances of the injury, it was revealed that in 68 (73.9\%) cases the injuries were sustained as a result of domestic and street injuries, and in $24(26.1 \%)$ cases when there was a car accident inside the passenger compartment. Among the damage to the organs of hearing (92), damage to the outer part of the ear (81) prevailed, while damage to the middle and inner ear was noted significantly. It was established that from the impact of blunt solid objects, the outer and middle ear were mainly damaged. Damage to the inner ear (labyrinth) and the temporal bone pyramid were observed in severe, combined head injuries.

Conclusions. Hearing injuries more often observed in males. Among the main causes of traumatic injuries are household and street injuries. The criteria for assessing the severity of damage to the outer ear may be the duration of the health disorder, and the middle ear - the amount of permanent loss of general disability, taking into account the presence of combined injuries. Traumatic injuries of BP recovered in $100 \%$ of those examined. Justification of the severity of damage is possible during complex studies: clinical, audiological, radiological, CT or MSCT studies.

KEY WORDS: hearing; damage; forensic assessment. 